\title{
The Biological Station at Barents Sea
}

$\mathrm{I}^{\mathrm{T}}$ will interest British biologists and especially fishery research workers to learn that a big new biological station is being built by the Academy of Sciences of the U.S.S.R. at Murmansk on the Barents Sea. The new biological station is intended for extensive research in morphology, anatomy, embryo. logy, physiology, biochemistry and ecology of sea organisms.

Owing to the penetration of the warm waters of the Atlantic into the Barents Sea, the fauna of the latter is extremely rich and diverse. Of importance is the fact that at Dalnye-Zelenets Bay the water is transparent to a depth of 10 metres, and that large stretches of the sea bottom are visible from the surface. The scientific workers at the station will make a detailed study of the problems of evolutionary physiology, embryology and the relationship of the fauna with changed hydrological conditions effected by the Gulf Stream.

The Murmansk biological station will supply biological material to the various research institutes and higher educational institutions of the U.S.S.R. Superintending the building of the station is a special commission consisting of S. A. Zernov (director of the station), L. A. Orbeli, V. I. Vernadsky and N. M. Knipovich, Prof. K. M. Deryugin of the University of Leningrad, Prof. L. N. Fedorov, director of the All Union Institute of Experimental Medicine, and Prof. E. M. Kreps.
The cost of building the Murmansk Station is estimated at $3 \frac{1}{2}$ million roubles, excluding equipment. A scientific library, the zoological, botanical, microbiological and hydrochemical laboratories and the libraries of other departments will be housed in the main building of the station. An aquarium designed for scientific work will be installed on the first floor of this building while several other aquaria, open to the public, will be erected in the basement of the building. Premises containing students' laboratories will be situated near the central building, and will also be equipped with large aquaria. Special interest is attached to an open-air concrete reservoir intended to accommodate large sea animals including seals.

The spawn of crabs will be brought from the Far East for acclimitization and breeding in the Barents Sea. A special vessel, 30 metres long, built for scientific work in the open sea will maintain uninterrupted communications between the station and the city of Murmansk.

At the beginning of this year, the Academy of Sciences of the U.S.S.R. commenced extensive work in the Dalnye-Zelenets Bay, east of the Kola Bay (Teriberka district, situated in the Northern Province) for the construction of this biological station, which will be the finest in the Soviet Union. The Soviet architect N. V. Ryumin and his assistants. have designed all the buildings.

\section{Irradiation of Plants with Neon Light}

A FTER years of experiments in Holland and elsewhere, an appreciable measure of success has recently been achieved in promoting the development of plants by irradiation with artificial light. J. W. M. Roodenburg and G. Zecher, in a paper in Philips Technical Review (Eindhoven) of July last describe recent technical developments, and show that it is now possible for the market gardener and the amateur horticulturist to employ irradiation on a practical scale.

The growth of plants is naturally intimately connected with their photosynthesis. As photosynthesis is most active in red light, it is necessary to use red rays. Twenty years ago neon light was suggested, but this light is not so easy to manipulate as glow lamp light, so further experiments were made with glow lamps. These showed that although the development of leaves was promoted, the general quality of the plants suffered, as the stems and stalks grew too 'leggy'. Experiments have now shown that provided the proper 'dosage' is given, neon light is exceptionally suitable for plant irradiation. The stems become thicker, the roots are stronger and frequently the formation of blooms and fruit is much promoted.

When neon lights were introduced for the irradia. tion of plants, they had already been employed for several years as luminous advertisements. For these purposes long glass tubes are used, into the ends of which two iron electrodes are fused. The tubes contain a neon filling at a pressure of approximately $10 \mathrm{~mm}$. They are run at a pressure of 3,000 volts and emit a comparatively small luminous flux per metre of tube-length. For use in damp forcing houses for the irradiation of plants, these tubes would be objectionable owing to the risk of shock ; moreover, their low brightness makes it difficult to obtain the best illumination. To get a satisfactory illumination, it was necessary to reduce the pressure to $1 \mathrm{~mm}$. or less. But at this pressure the iron electrodes disintegrated rapidly, so that the life of a tube was only a few hours. A solution was obtained by using hot cathodes similar to those used in gas-discharge tubes for highway lighting. This enables the tubes to be run at low pressures.

The hot cathode tubes are connected directly to 220 volts mains supply, through a series-connected 'choke' coil. A simple device is employed for starting up the tube, since the running voltage is too low to initiate the first electric discharge through the lowpressure neon gas. During the burning of the lamp, the cathode suffers practically no disintegration and the light output remains uniform. After 2,000 hours 